\title{
Technological Aesthetics of Modern Architecture as an Expression of Structure
}

\author{
OUYANG Fangxin ${ }^{1}$, CHEN Huilian² \\ 1.School of Civil Engineering and Architecture, Wuhan Polytechnic University, P.R.China,430040 \\ 3461773@qq.com
}

2.School of Urban Architecture, Wuchang University of Technology, P.R.China, 430223

178580498@qq.com

Keywords: Mechanical Structure, Support System, Sense of Beauty, Building Materials

Abstract: Given that architectural aesthetics, as a combination of both art and engineering technologies, has been drawing more and more attention, it's has been architects' top priority how to strive a balance between them to achieve real structural aesthetics with an integration of stiffness and softness.

As comprehensive arts, architecture contains both structural design based on mechanics and architectural design with stress on aesthetics. Due to differences in their foundations and restrictions and binding principles, they are not naturally united and need architects to mix both architectural design and structural design.

\section{Structure and Form}

In ancient times, the conflict between architectural structure and form was not prominent because an architect of that age, as an artists and engineer, could have thorough thinking of both of them from the very beginning. Therefore, the structure and form of their works were fully combined. For example, ancient Chinese wooden buildings stood out in the roof forms including gable and hip roofs, overhanging gable roofs, flush gable roofs, pyramidal roofs and round ridge roofs. And big gable and hip roofs produce a sense of stableness and harmony. Also, the ingenious association of straight and curved lines on the roofs constructs upturned eaves, not only expanding the lighting surface and being beneficial to the drainage of rainwater, but also adding a sense of beauty to the buildings.

However, the relationship between structure and form in modern times has become different from that of ancient times. It's noted that structural technologies affect buildings to a large extent and thus architects are often deemed as dancers with fetters. In pursuit of perfection, they have to resort to all decorative and technological tools to seal the structure for a quite long period.

Thanks to the development of modern science and technologies, engineering structure has become 
an independent scientific system and major detached from architecture. In the meantime, structural technologies can channel new contents into architecture and advances in structure, material, product and construction have laid a solid foundation for architects to give full play to their talents. Also, form has been gaining more and more attention from architects. Gradually, form aesthetics of classical architecture passed down from ancient Greek and Rome has been replaced by technological aesthetics of modern architecture.

\section{The Relationship Between Structure and Form}

As human beings, different from animal, have their mental and spiritual activities, they have aesthetic and spiritual requirements of buildings where they live or work. For example, when Xiao He built WeiYang Palace for Liu Bang, founder of the Han dynasty, he held that "The building where an emperor lives should be grave and dignified although he feels at home wherever he lives, or his authoritativeness cannot be fully represented," implying that architecture can cultivate the solemn atmosphere.

If architecture is regarded as a kind of symbolic art, the architectural form is a kind of artistic creation. Accordingly, architects, in addition to responding to architectural demands on space and size, can apply some abstract geometrical shapes while paying attention to the unification and changes of ratio, balance, symmetry, color, texture and rhythm of lines, surfaces and bodies, so as to achieve an artistic environment.

As the skeleton of architectural space and visual space, structure has a great influence on the architectural form after all the skeleton determines the size of the form and clarifies the appearance, both of which are built on the skeleton. As a result, whatever form an architect wishes to design shall be based on the structure.

\section{Structure and the Exterior Form of a Building}

The exterior form of a building stands at the core of the architectural forms and directly decides the image of a building. But the exterior form shall not come out of nothing and cannot be set by architects at will. To a great extent, it is a reflection of interior space of a building.

In the process of construction, architects often resort to some physical materials to divide space in conformity to functions. Additionally, they will bring into full play the mechanical properties of materials and ensure that the employment of all the materials follow the loading transfer rule so that each and every related part is of a certain amount of stiffness and fits static equilibrium followed by the being of structure. Namely, structure, as a tool to divide space and fulfill architectural functions, 
will also outline the exterior form of a building and even its exterior image.

\section{Structure and Architectural Surface}

The relationship between structure and architectural surface can be elaborated from two aspects. First, instead of being the purpose, structure serves the architectural surface. And the surface must be closed connected to the structure in order to resist the forces of mechanics. So any discussion of architectural surface without attention given to surface is meaningless. Second, the direct expression of the structural form is architectural surface. And reasonable organization of structural components can bring about colorful surfaces. However, the aesthetic effect shall also be evaluated on the basis of the support and economy of the interior structure. Although the skeleton itself is more function-oriented, it can raise the poetic effect of the whole building.

\section{Form Aesthetics as an Expression of Structure}

In order to take advantage of structural forms beneficial to architectural aesthetics, modern architectural spatial forms can make full use of form aesthetics complying with the mechanic rule and principle so as to underpin the artistic effect of a building. The mentioned form aesthetics refers to forms, in the art arena, of some appeal on people's spirit. People will feel happy and satisfied when some of visual forms such as lines, patterns and colors correspond to the underlying mechanism inside them. Thus, these kinds of visual forms are of aesthetic and vice versa.

Form aesthetics of a building is displayed in structural balance and stability, rhythm and tempo, continuity and gradual changes, as well as form and texture. It's due to the structure that each and every part of a building meet the principle of practice, economy and beauty to a different extent,

For example, the body of Palazzeto Dellospori of Rome is a ribbed concrete shell dome consisting of a casing, bearing ring and lower support component. From the perspective of structure, the load is transferred to the base by 36 straight, Y-shaped and fork-type columns along the tangent line surrounding the casing or single and duplex oblique cylinder still along the tangent line. Such a simple and clear structure is filled with decorativeness and rhythm.

The natural manifestation of structure is to disclose those parts of aesthetic after all structure does not definitely mean beauty. Architectural aesthetics can be achieved with architects' artistic creations. Then, a building can serve the purposed of utility, economy and beauty. Ray Stadium in US (as shown in the picture) has a clear stress structure to achieve balance. Besides, materials of cables and arch feature construction convenience. In the surrounding of the inclined arch lie support steel pillars with a spacing interval of 2.4 meters. These pillars double as vertical mullions of doors 
and windows, thus producing an architectural form of rhythm and with vertical intervals. It's acknowledged as a wonderful cable-net structure of long span.

\section{Misunderstandings}

As a synthesis which is required to satisfy demands of multiple sides, architecture will serve different purposed under varying conditions. Consequently, any one-sided emphasis on structure will definitely result in formalism as structure is weighed above any other demands and deemed as necessary.

Structure, is essentially a method to help architecture to achieve its functions. The most important function of structure is support followed by the expression of aesthetics of form. On the contrary, any adoption of unnecessary and nonbearing structure only for exterior ornamentations begins at the wrong end. Even some architects not specialized in structural properties prefer unpractical decorations as an attempt to beautify architecture, which, however, increase the weight, cost of a building, and go against its functions. For example, the building below obviously is against structural mechanics for the form of triangle support shall be thicker, not thinner downward, which fully demonstrates that its architect creates those mechanically meaningless structure in pursuit of novelty in form.

On the other hand, not all buildings are fit to expose their structures. Apart from structure, quite a number of buildings have some equipment, pipelines inside which shall be hidden from the eyes of the public. What we advocate as an expression of structure is to properly display the substantive beauty of a building in the light of the circumstances instead of being totally exposed. Nevertheless, the idea of "an expression of structure" has driven a group of architects into purely exposing everything inside the building and the whole structure, which has been stripped of any aesthetic pursuit of a building and has not taken into consideration the prerequisite of all acoustics, thermal engineering, fire prevention and dust prevention.

\section{Conclusion}

In modern times, the rapid growth of architectural materials has shifted people's aesthetic perception of architecture accompanied by the replacement of technological aesthetics of modern architecture with the form aesthetics of classical architecture. Thus, the expression of structure in architectural creations has been on the rise step by step. It's recognized that architects should design forms according to the structure so that they can pay equal attention to aesthetic form and mechanical structure. It's encouraged that the perfect integration of both mechanics and aesthetics 
shall be accomplished based on existent structural technologies and subjective architectural thinking.

\section{References:}

[1] Xu Zipeng. 2014. A Brief Analysis of Technological Aesthetics in Architectural Design [J]. Architectural Engineering Technology and Design (6): 108-109.

[2] Wang Jianghua. 2014. Form-Structure Aesthetics and Modern Architecture [J]. Journal of Human Settlements in West China (2): 078-083.

[3] Chen Hao. 2008. Artistic Representation of Structure-A Brief Analysis of Artistic Representation of High Techniques [J]. Sichuan Architecture (Vol 28, 3): 026-027. 